Tohoku J. Exp. Med., 2004, 204, 289-298

\title{
Increased mRNA Expression of Th1-Cytokine Signaling Molecules in Patients with HTLV-I-Associated Myelopathy/Tropical Spastic Paraparesis
}

\author{
Yoshihiro Nishiura, Tatsufumi Nakamura, ${ }^{1}$ Naomi Fukushima, ${ }^{1}$ Ryozo \\ Moriuchi, ${ }^{1}$ Shigeru Katamine ${ }^{1}$ and Katsumi Eguchi \\ First Department of Internal Medicine, ${ }^{I}$ Department of Molecular Microbiology \\ and Immunology, Graduate School of Biomedical Sciences, Nagasaki University, \\ Nagasaki, Japan
}

Nishiura, Y., Nakamura, T., Funushima, N., Moriuchi, R., Katamine, S. and EguchI, K. Increased mRNA Expression of Th1-Cytokine Signaling Molecules in Patients with HTLV-I-Associated Myelopathy/Tropical Spastic Paraparesis. Tohoku J. Exp. Med., 2004, 204 (4), 289-298 — Expression of inflammatory cytokines derived from Th1 cell population is increased in patients with human T-lymphotropic virus type I (HTLV-I)-associated myelopathy/tropical spastic paraparesis (HAM/ TSP). It has been shown that cytokine signaling molecules, including transcription factors T-bet and GATA-3, interleukin-12 receptor $\beta 2$ (IL-12R $\beta 2$ ) and suppressors of cytokine signaling (SOCS), such as SOCS1, are important in differentiation of naive $\mathrm{T}$ cells into Th1 helper T cells. To assess the immunological status from the standpoint of cytokine signaling in patients with HAM/TSP, we analyzed mRNA expression of these cytokine signaling molecules in peripheral blood mononuclear cells using quantitative RT-PCR. Twenty-eight HAM/TSP patients, nine HTLV-I-infected individuals without HAM/TSP and twenty-two HTLV-I-uninfected individuals were included in this study. Expression of T-bet, GATA-3, IL-12R $\beta 2$ and SOCS1 was significantly increased in HAM/TSP patients in comparison with HTLV-I-uninfected individuals. In contrast, expression of SOCS3, a marker for Th2 cells, was significantly decreased in HTLV-I-infected individuals. These results indicate that HAM/TSP patients are associated with increased Th1 and decreased Th2 cytokine signaling activities. - HAM/TSP; HTLV-I; cytokine signaling; Th1; Th2

(C) 2004 Tohoku University Medical Press

Received July 12, 2004; revision accepted for publication October 20, 2004.

Address for reprints: Yoshihiro Nishiura, First Department of Internal Medicine, Graduate School of Biomedical Sciences, Nagasaki University, 1-7-1 Sakamoto, Nagasaki 852-8501, Japan.

e-mail: yoshihironishiura@hotmail.com 
Human T-lymphotropic virus type I (HTLV-I) is the etiological agent of a rapidly progressive lymphoproliferative malignancy, known as adult T-cell leukemia (ATL) (Yoshida 2001), and of a chronic spastic myelopathy, known as HTLV-Iassociated myelopathy/tropical spastic paraparesis (HAM/TSP) (Osame et al. 1986). HTLV-I infection has also been associated with other inflammatory diseases, such as arthropathy, uveitis, polymyositis and alveolitis (Hollsberg 1999). Of these HTLV-I-related inflammatory diseases, $\mathrm{HAM} / \mathrm{TSP}$ is the paradigm. It is characterized by perivascular cuffing accompanied by parenchymal lymphocytic infiltration in the spinal cord (Akizuki et al. 1987). While greater insights have been gained into the pathological mechanisms operative in HAM/TSP (Osame 2002), it is still unclear why only a minor proportion of HTLV-I-infected individuals develop HAM/TSP and other HTLVI-associated inflammatory diseases.

Numerous immunological abnormalities are known to exist in patients with HAM/TSP (Nakamura 2000a). Previously, cytokine studies in HAM/TSP patients have revealed elevated serum, cerebrospinal fluid (CSF) and $\mathrm{CD}^{+}$cell culture supernatant levels of interferon- $\gamma($ IFN- $\gamma$ ) (Kuroda and Matsui 1993; Nishiura et al. 1996; Furuya et al. 1999) and high intracellular IFN$\gamma^{+} /$interleukin- $4^{+}\left(\mathrm{IL}-4^{+}\right)$cell ratio in $\mathrm{CD} 4^{+} \mathrm{T}$ cells (Horiuchi et al. 2000), suggesting that the immunological state of HAM/TSP patients is under Th1 activation (Nakamura et al. 2000b). On the other hand, HTLV-I infection also causes production of Th2 cytokines (Mogensen and Paludan 2001). Thus, the immunological state of HTLV-I-infected individuals is still obscure, with data showing upregulation of both Th1 and Th2 cytokine production (Carvalho et al. 2001) and production of only Th1 cytokine in HTLV-I-infected cells (Hanon et al. 2001).

In differentiation of naive T cells into Th1 or Th2 helper T cells, cytokine signaling plays an

TABLE 1. Oligonucleotide primer sequences and sizes of PCR products

\begin{tabular}{|c|c|c|}
\hline & Sequence & Size \\
\hline$\beta 2 \mathrm{~m}$ & $\begin{array}{l}\text { forward, CCAGCAGAGAATGGAAAGTC } \\
\text { reverse, GATGCTGCTTACATGTCTCG }\end{array}$ & $391 \mathrm{bp}$ \\
\hline IL-12R $\beta 2$ & $\begin{array}{l}\text { forward, TTCACCCACTCACСТTCTCC } \\
\text { reverse, CCAGTTCCTAAGACTCCСCC }\end{array}$ & $243 \mathrm{bp}$ \\
\hline T-bet & $\begin{array}{l}\text { forward, CCCCAAGGAATTGACAGTTG } \\
\text { reverse, GGGAAACTAAAGCTCACAAAC }\end{array}$ & 317 bp \\
\hline GATA-3 & $\begin{array}{l}\text { forward, CTACGGAAACTCGGTCAGG } \\
\text { reverse, CTGGTACTTGAGGCACTCTT }\end{array}$ & $372 b p$ \\
\hline SOCS1 & $\begin{array}{l}\text { forward, AGACCCCTTCTCACСТCTTG } \\
\text { reverse, CTGCACAGCAGAAAATAAAGC }\end{array}$ & $245 \mathrm{bp}$ \\
\hline SOCS3 & $\begin{array}{l}\text { forward, CTTCAGCATCTCTGTCGGAAGA } \\
\text { reverse, GCATCGTACTGGTCCAGGAACT }\end{array}$ & $104 \mathrm{bp}$ \\
\hline HTLV-I tax & $\begin{array}{l}\text { forward, AAACAGCCCTGCAGATACAAAGT } \\
\text { reverse, ACTGTAGAGCTGAGCCGATAACG }\end{array}$ & $247 \mathrm{bp}$ \\
\hline
\end{tabular}


important role. Interleukin-12 receptor/signal transducers and activators of transcription 4 (IL12R/STAT4) and IL-4R/STAT6 signaling are involved in Th1 and Th2 differentiation, respectively (Murphy et al. 2000). In addition, T-bet, a member of the T-box family, was recently cloned as a Th1-specific transcription factor (Szabo et al. 2000). Therefore, both IL-12R/STAT4 signaling and T-bet work cooperatively in Th1 differentiation, and IL-4R/STAT6 signaling induces GATA-3 activation, one of the Th2-specific transcription factors, in Th2 differentiation (Zheng and Flavell 1997).

Recently, the importance of negative regulation of cytokine signal transduction in the differentiation and homeostasis of the immune system has become somewhat clearer (Yasukawa et al. 2000). The suppressor of cytokine signaling (SOCS) family is a representative of the negative regulators which act through a feedback mechanism or an inhibitory signal to the Janus kinases (JAK)/STAT systems in cytokine signaling (Krebs and Hilton 2001). In this system, SOCS1 is in- duced by IFN- $\gamma$ receptor (IFN- $\gamma$ R)/STAT1 signaling and inhibits IL-4R/STAT6 signaling concomitant with the negative feedback to its own JAK/STAT1 signaling (Losman et al. 1999; Yasukawa et al. 2000). Although SOCS3 is induced by a number of humoral factors, such as IL-2, IL-6, IL-10, growth hormone, prolactin and leptin, with simultaneous negative feed back to their own JAK/STATs (Alexander 2002), recent data indicate that SOCS3 also inhibits IL-12R/ STAT4 signaling (Egwuagu et al. 2002).

These findings suggest that up-regulation of SOCS 1 expression, based on activation of IFN- $\gamma$ signaling, inhibits Th2 differentiation by blocking the IL-4R/STAT6 signaling pathway, and that down-regulation of SOCS3 expression leads to Th1 differentiation. Indeed, Egwuagu et al. (2002) have reported that Th1 cells express significantly higher levels of SOCS1 than SOCS3 and expression levels of each SOCS protein are reversed inTh2 cells, indicating that either SOCS 1 or SOCS3 protein is a marker for Th1 cells or Th2 cells, respectively. In addition, very recently, Seki

TABLE 2. PCR cycling conditions

\begin{tabular}{lcccc}
\hline & Denaturation & Aannealing & Extensio & Cycles \\
\hline$\beta 2 \mathrm{~m}$ & $95^{\circ} \mathrm{C}, 15 \mathrm{~s}$ & $58^{\circ} \mathrm{C}, 5 \mathrm{~s}$ & $72^{\circ} \mathrm{C}, 15 \mathrm{~s}$ & 32 \\
IL-12R $\beta 2$ & $95^{\circ} \mathrm{C}, 15 \mathrm{~s}$ & $65^{\circ} \mathrm{C}, 5 \mathrm{~s}$ & $72^{\circ} \mathrm{C}, 12 \mathrm{~s}$ & 45 \\
T-bet & $95^{\circ} \mathrm{C}, 15 \mathrm{~s}$ & $62^{\circ} \mathrm{C}, 5 \mathrm{~s}$ & $72^{\circ} \mathrm{C}, 15 \mathrm{~s}$ & 45 \\
GATA-3 & $95^{\circ} \mathrm{C}, 15 \mathrm{~s}$ & $62^{\circ} \mathrm{C}, 5 \mathrm{~s}$ & $72^{\circ} \mathrm{C}, 15 \mathrm{~s}$ & 45 \\
SOCS1 & $95^{\circ} \mathrm{C}, 15 \mathrm{~s}$ & $62^{\circ} \mathrm{C}, 5 \mathrm{~s}$ & $72^{\circ} \mathrm{C}, 10 \mathrm{~s}$ & 45 \\
SOCS3 & $95^{\circ} \mathrm{C}, 15 \mathrm{~s}$ & $60^{\circ} \mathrm{C}, 5 \mathrm{~s}$ & $72^{\circ} \mathrm{C}, 10 \mathrm{~s}$ & 45 \\
HTLV-I tax & $95^{\circ} \mathrm{C}, 15 \mathrm{~s}$ & $55^{\circ} \mathrm{C}, 5 \mathrm{~s}$ & $72^{\circ} \mathrm{C}, 10 \mathrm{~s}$ & 40 \\
\hline
\end{tabular}

s, seconds.

TABLE 3. mRNA expression of cytokine signaling molecules

\begin{tabular}{lccc}
\hline & HAM/TSP patints & $\begin{array}{c}\text { HTLV-I-infected individuals } \\
\text { without HAM/TSP }\end{array}$ & HTLV-I-uninfected individuals \\
\hline T-bet & $0.260 \pm 0.043$ & $0.241 \pm 0.100$ & $0.118 \pm 0.028$ \\
GATA-3 & $0.167 \pm 0.040$ & $0.115 \pm 0.051$ & $0.022 \pm 0.005$ \\
IL-12R $\beta 2$ & $0.321 \pm 0.126$ & $0.288 \pm 0.104$ & $0.114 \pm 0.023$ \\
SOCS1 & $0.338 \pm 0.062$ & $0.147 \pm 0.038$ & $0.035 \pm 0.007$ \\
SOCS3 & $4.860 \pm 0.818$ & $6.714 \pm 1.467$ & $13.234 \pm 1.385$ \\
\hline
\end{tabular}



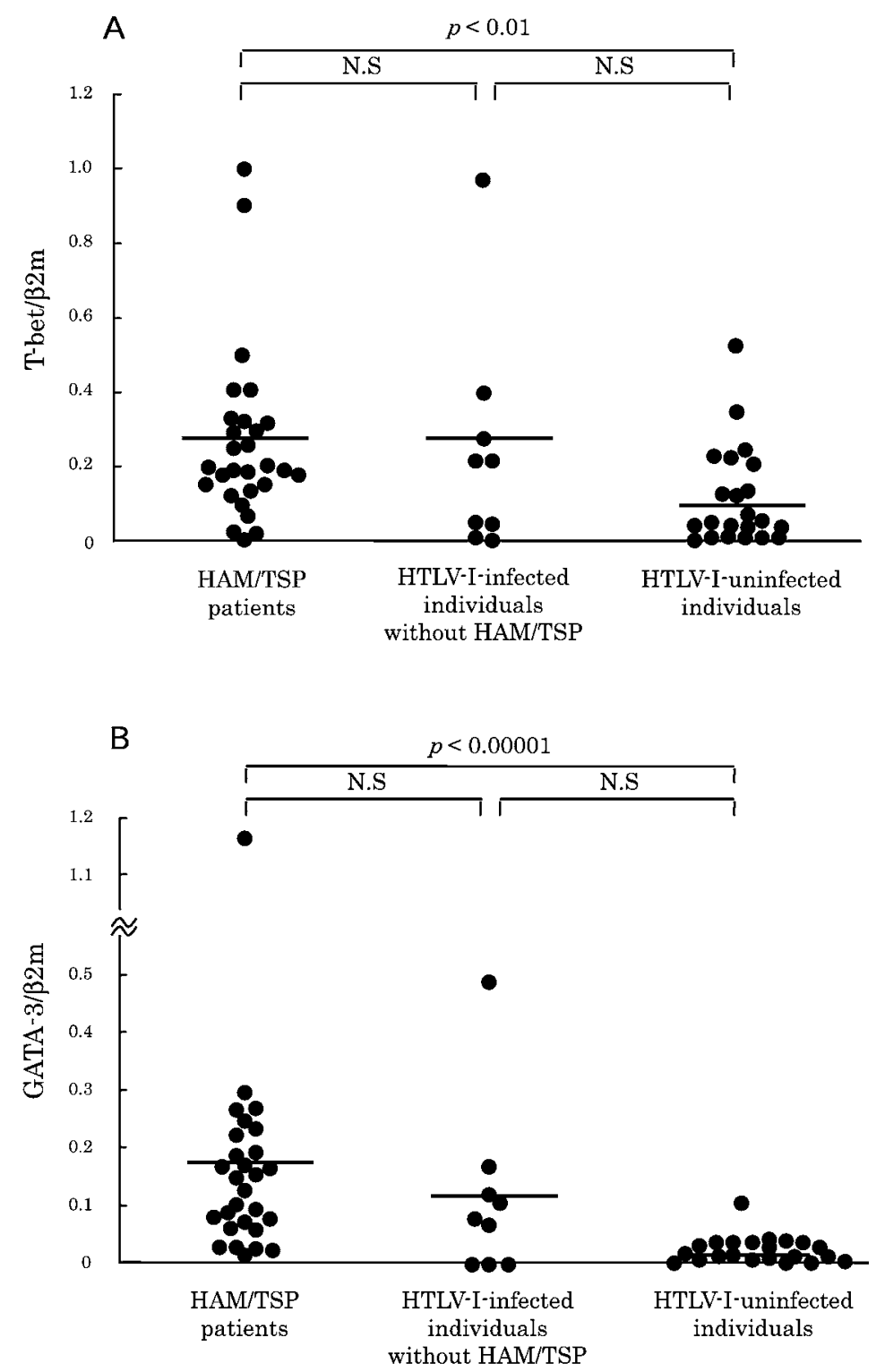

Fig. 1. Comparison of mRNA expression of T-bet and GATA-3 in PBMC. mRNA expression of both T-bet (A) and GATA-3 (B) in PBMC was significantly increased in HAM/TSP patients compared to HTLV-I-uninfected individuals. Although mRNA expression of T-bet and GATA-3 appeared to be higher in HTLV-I-infected individuals without HAM/TSP than in HTLV-I-uninfected individuals, this difference was not statistically significant. Mann-Whitney's U-test was used for statistical analysis.

et al. (2003) have demonstrated that SOCS3 is predominantly expressed in Th2 cells.

To further clarify the molecular basis of the Th1/Th2 state from the stand-point of cytokine signaling in HTLV-I-infected individuals with and without HAM/TSP, we investigated mRNA expression of T-bet, GATA-3, IL-12R $\beta 2$, SOCS 1 and SOCS3 in peripheral blood mononuclear cells (PBMC) by quantitative RT-PCR. In addition, we analyzed the relationship between cytokine signaling molecules and HTLV-I tax mRNA expression in patients with HAM/TSP, compared to HTLV-I-infected individuals without HAM/TSP. 


\section{Materials ANd Methods}

\section{Subjects}

Twenty-eight HAM/TSP patients (6 men and 22 women; mean age, 58.5 years; age range, 29-78 years) were included in the study. The diagnosis of HAM/TSP was based on previously described criteria (Osame 1990). Control subjects comprised of 9 HTLV-I-infected individuals without HAM/TSP (2 men and 7 women; mean age, 60.4 years; age range, 26-69 years) and $22 \mathrm{HTLV}$ I-uninfected individuals ( 8 men and 14 women; mean age, 54.5 years; age range, 26-75 years). The 9 HTLV-I-infected individuals without HAM/ TSP included patients with cerebrovascular accident $(n=2)$, essential tremor $(n=2)$, tension-type headache $(n=1)$, spinocerebellar degeneration $(n=1)$, amyotrophic lateral sclerosis $(n=1)$, cervical spondylosis $(n=1)$, diabetic polyneuropathy $(n=1)$, whereas the 22 HTLV-I-uninfected individuals included patients with cerebrovascular accident $(n=5)$, tension-type headache $(n=3)$, Parkinson disease $(n=2)$, spinocerebellar degeneration $(n=2)$, multiple sclerosis (remission phase, $n=2)$, migraine $(n=2)$, cervical spondylo- sis $(n=2)$, essential tremor $(n=1)$, epilepsy $(n=1)$, Bell's palsy $(n=1)$, and brain tumor $(n=1)$. None of the patients had been treated with immunomodulatory drugs, including corticosteroids and interferon- $\alpha$ during the last one year. Informed written consent was obtained from all patients in the study. This research was approved by the review boards of Graduate School of Biomedical Sciences, Nagasaki University.

\section{RNA isolation and quantitative RT-PCR} analysis

PBMC were separated by Ficoll-Paque Plus (Amersham Biosciences, Uppsala, Sweden). Total cellular RNA was extracted from PBMC by Sepasol-RNA I super (NACALAI TESQUE, INC., Kyoto). cDNA was synthesized from 2.0 $\mu \mathrm{g}$ RNA treated with RQ1 RNase-Free DNase (Promega, Madison, WI, USA) using Oligo (dT) 12-18 primer (Promega). M-MLV reverse transcriptase $(1 \mu 1)$ (Promega) and 25 units of Ribonuclease inhibitor (Promega) were used in a total volume of $25 \mu \mathrm{l}$. For quantitative analysis of IL-12R $\beta 2$, T-bet, GATA-3, SOCS1, SOCS3, HTLV-I Tax and $\beta 2$-microglobulin $(\beta 2 \mathrm{~m})$ in

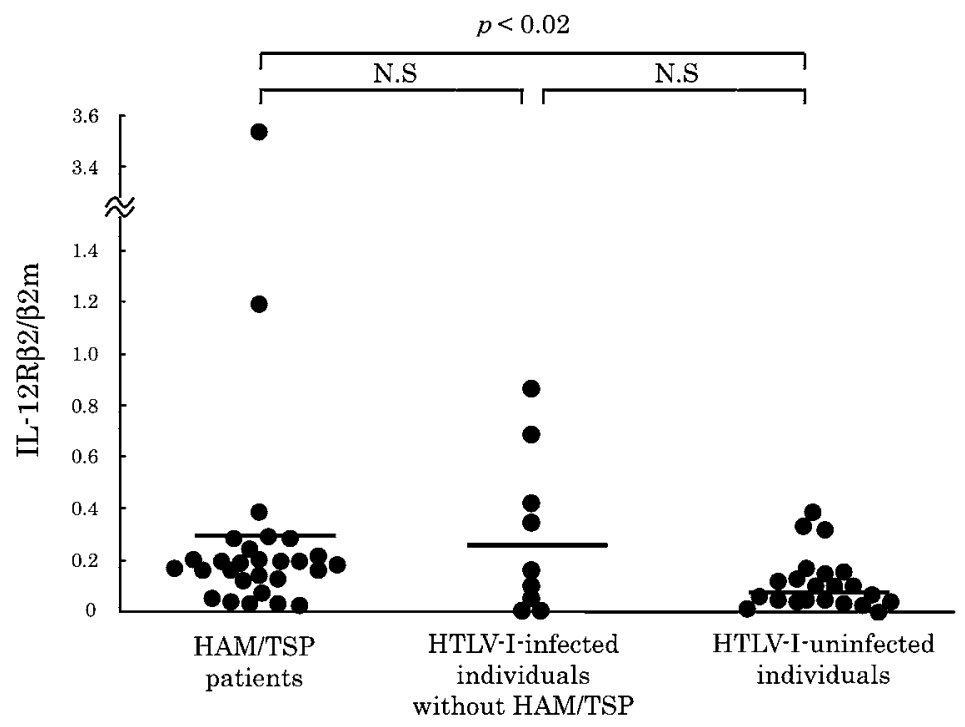

Fig. 2. Comparison of mRNA expression of IL-12R $\beta 2$ in PBMC. mRNA expression of IL-12R $\beta 2$ in PBMC was significantly higher in HAM/TSP patients than in HTLV-I-uninfected individuals. Although mRNA expression of IL-12R $\beta 2$ seemed to be higher in HTLV-I-infected individuals without HAM/TSP than in HTLV-I-uninfected individuals, this difference was not statistically significant. Mann-Whitney's U-test was used for statistical analysis. 
PBMC, real-time quantitative RT-PCR was performed in a Light-Cycler FastStart DNA Master (Roche Diagnostics, Mannheim, Germany) based on general fluorescence detection with SYBR Green. The primer sequences and the sizes of the PCR products are shown in Table 1; and PCR conditions are shown in Table 2. For quantitative RT-PCR, bulk cDNA derived from cell lines were used as standards. HCT-1, derived from CSF cells from a patient with HAM/TSP, was used for IL-12R $\beta 2$, SOCS1 and SOCS3; MT-2 was used for $\beta 2 \mathrm{~m}$, T-bet and HTLV-I Tax; and Jurkat was used for GATA-3. Each mRNA expression was evaluated by normalization to $\beta 2 \mathrm{~m}$.

\section{Statistical analysis}

Results were expressed as mean \pm standard error of the mean. Differences between groups were tested for statistical significance by use of the nonparametric Mann-Whitney's U-test. Correlation analyses were performed by use of nonparametric Spearman's rank correlation test. The level of significance was set at $p=0.05$.

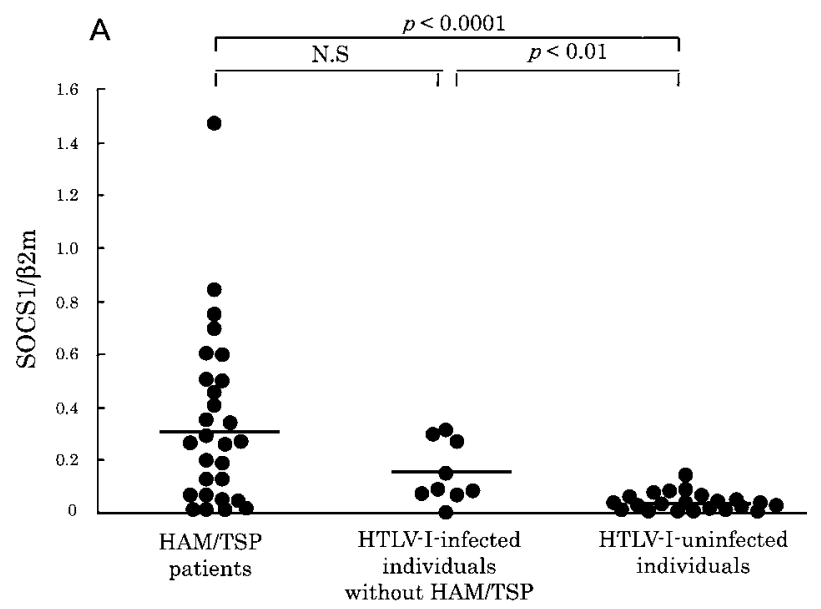

\section{Results}

mRNA expression of each cytokine signaling molecules in PBMC was measured by real-time quantitative RT-PCR. Each mRNA expression was evaluated by normalization to $\beta 2 \mathrm{~m}$. The value of each mRNA expression was shown in Table 3. As shown in Fig. 1A and 1B, mRNA expression. of both T-bet and GATA-3 was significantly increased in PBMC of HAM/TSP patients compared to HTLV-I-uninfected individuals. In addition, mRNA expression of IL- $12 \mathrm{R} \beta 2$ was significantly higher in HAM/TSP patients than in HTLV-I-uninfected individuals (Fig. 2). Although mRNA expression of T-bet, GATA-3 and IL-12R $\beta 2$ seemed to be higher in HTLV-I-infected individuals without HAM/TSP than in HTLV-I-uninfected individuals, these differences were not statistically significant. In addition, no significant differences in mRNA expression were found among HTLV-Iinfected individuals with or without HAM/TSP.

mRNA expression of SOCS1 in PBMC was significantly increased in HAM/TSP patients and

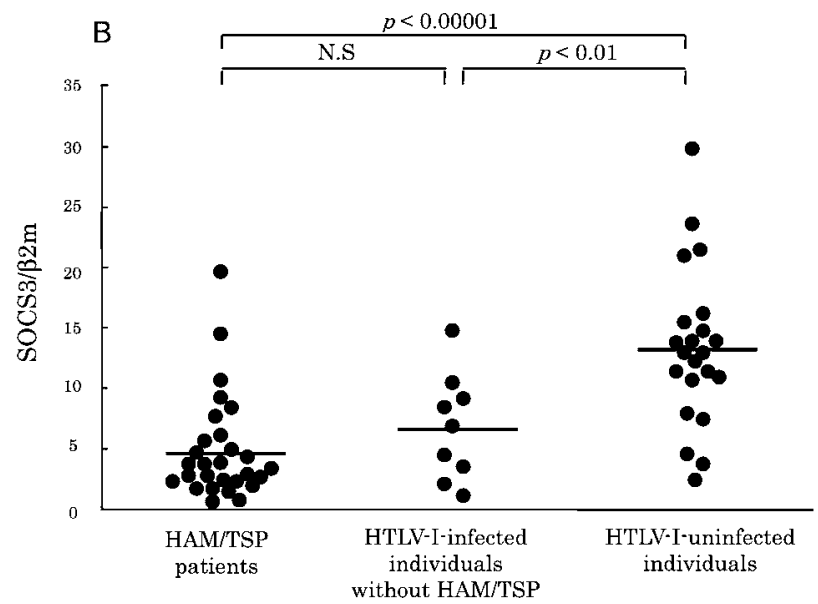

Fig. 3. Comparison of mRNA expression of SOCS1 and SOCS3 in PBMC. mRNA expression of SOCS1 in PBMC (A) was significantly higher in HAM/TSP patients and HTLV-I-infected individuals without HAM/TSP than in HTLV-I-uninfected individuals. Although mRNA expression of SOCS1 seemed to be higher in HAM/TSP patients than in HTLV-I-infected individuals without HAM/TSP, this difference was not statistically significant. Conversely, mRNA expression of SOCS3 in PBMC (B) was significantly decreased in both groups of HTLV-I-infected individuals compared to HTLV-I-uninfected individuals. There was no significant difference in mRNA expression of SOCS3 between HAM/TSP patients and HTLV-I-infected individuals without HAM/TSP. Mann-Whitney's U-test was used for statistical analysis. 
A

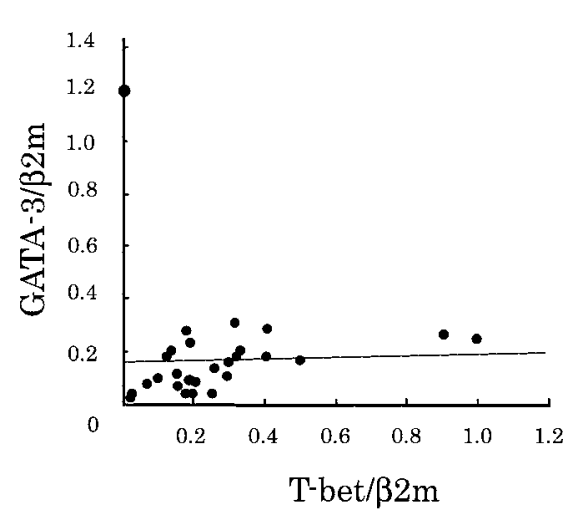

B

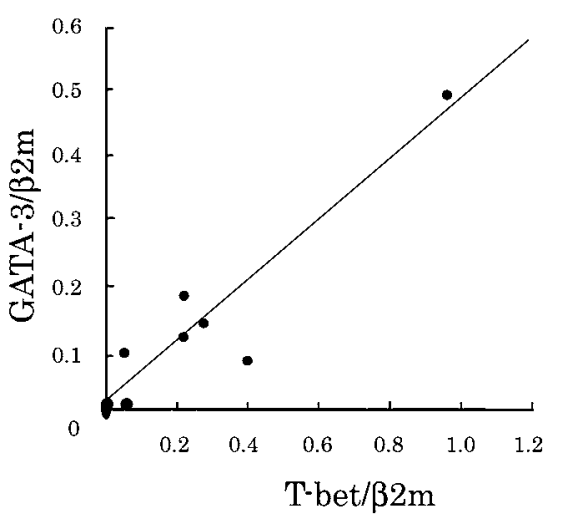

Fig. 4. Correlation between T-bet and GATA-3 mRNA expression among HTLV-I-infected individuals. mRNA expression of both transcription factors showed moderately positive correlation in HAM/ TSP patients and strongly positive correlation in HTLV-I-infected individuals without HAM/TSP, respectively. Nonparametric Spearman's rank correlation test was used for statistical analysis. A: HAM/TSP patients ( $\mathrm{rs}=0.393, p=0.041$ ), B: HTLV-I-infected individuals without HAM/TSP (rs $=0.754, p=0.033$ ).
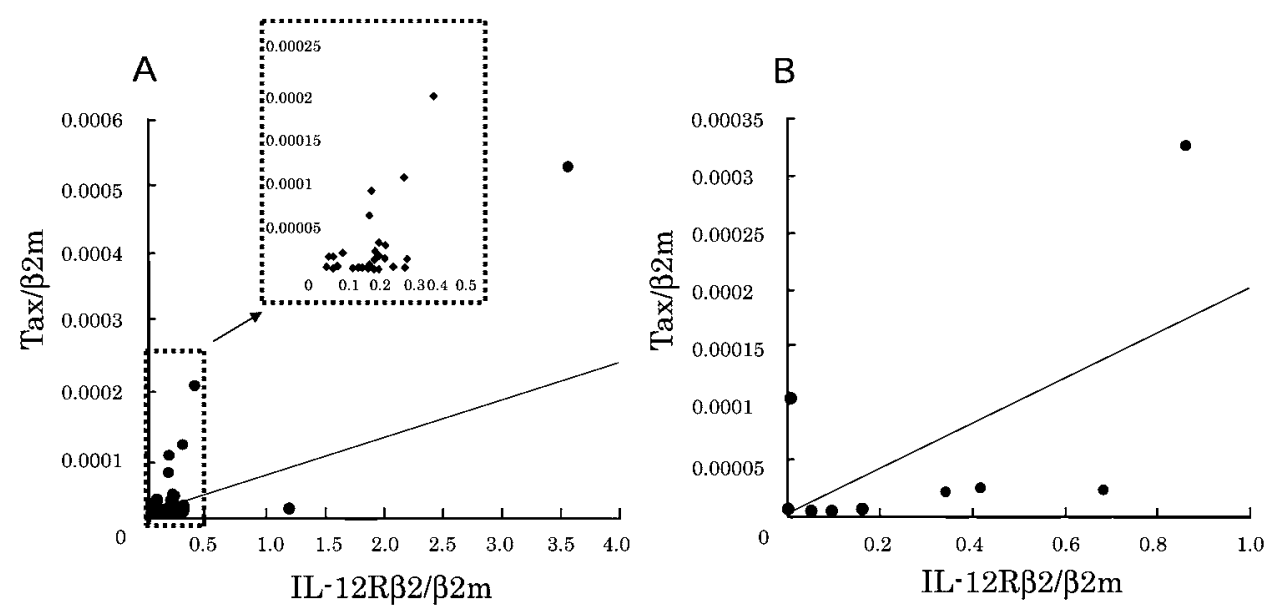

Fig. 5. Correlation between IL-12R $\beta 2$ and HTLV-I tax mRNA expression among HTLV-I-infected individuals. There was moderately positive correlation in only HAM/TSP patients, but not HTLV-I-infected individuals without HAM/TSP. Nonparametric Spearman's rank correlation test was used for statistical analysis.

A: HAM/TSP patients ( $r s=0.380, p=0.048$ ), B: HTLV-I-infected individuals without HAM/TSP ( $r s$ $=0.197, p=0.367)$.

HTLV-I-infected individuals without HAM/TSP, compared to HTLV-I-uninfected individuals (Fig. $3 \mathrm{~A})$. Conversely, mRNA expression of SOCS3 was significantly decreased in HTLV-I-infected individuals with HAM/TSP and without HAM/ TSP, compared to HTLV-I-uninfected individuals (Fig. 3B). However, no significant difference in mRNA expression of SOCS3 was found between
HTLV-I-infected individuals with or without $\mathrm{HAM} / \mathrm{TSP}$.

In HTLV-I-infected individuals, increased mRNA expression of SOCS1 in PBMC indicated up-regulation of IFN- $\gamma$ signaling, and decreased mRNA expression of SOCS3 in PBMC indicated down-regulation of IL-4 signaling. Moreover, GATA-3 mRNA expression seemed to also be up- 
regulated in HTLV-I-infected individuals. Therefore, we analyzed the correlation between T-bet and GATA-3 mRNA expression in HTLV-Iinfected individuals. As shown in Fig. 4, mRNA expression of both transcription factors showed moderately positive and strongly positive correlation in HAM/TSP patients ( $\mathrm{rs}=0.393 ; p=0.041$ ) and in HTLV-I-infected individuals without HAM/TSP ( $\mathrm{rs}=0.754 ; p=0.033$ ), respectively.

Next, we analyzed the correlation between either T-bet, SOCS1 or IL-12R $\beta 2$ and HTLV-I tax mRNA expression. There were no correlations between either T-bet or SOCS1 and HTLV-I tax mRNA expression in both HAM/TSP patients (T-bet vs. HTLV-I tax: $r s=0.050 ; p=0.398$, SOCS1 vs. HTLV-I tax: $\mathrm{rs}=0.080 ; p=0.678$ ) and HTLV-I-infected individuals without HAM/ TSP (T-bet vs. HTLV-I tax: $r s=0.029 ; p=0.467$, SOCS1 vs. HTLV-I tax: rs $=-0.067 ; p=0.850$ ) (data not shown). However, as shown in Fig. 5, there was a moderately positive correlation between IL-12R $\beta 2$ and HTLV-I tax mRNA expression in HAM/TSP patients ( $\mathrm{rs}=0.380 ; p=0.048$ ), but not in HTLV-I-infected individuals without $\mathrm{HAM} / \mathrm{TSP}$ (rs $=0.197 ; p=0.367$ ).

\section{Discussion}

This is the first ex vivo analysis of Th1/Th2related cytokine signaling molecules in HTLV-Iinfected individuals. Firstly, to clarify the molecular mechanism of Th1 activation in HTLV-Iinfected individuals, we focused mRNA expression of T-bet which are master switches in Th1 differentiation (Grogan and Locksley 2002; O'Shea and Paul 2002). Expression of T-bet mRNA in PBMC was increased in HAM/TSP patients than in HTLV-I-uninfected individuals.

Secondly, we showed significantly increased SOCS 1 mRNA expression concomitant with the decreased SOCS3 mRNA expression in PBMC of HTLV-I-infected individuals compared to HTLVI-uninfected controls. Increased SOCS1 mRNA expression strongly suggests that both IFN- $\gamma$ and IL-12 signaling are up-regulated, and conversely, decreased SOCS3 mRNA expression suggests
IL-4 signaling is down-regulated in HTLV-Iinfected individuals. Alternatively, there might exist more Th1 cells and fewer Th2 cells in PBMC of HTLV-I-infected individuals compared to HTLV-I-uninfected individuals, if the distinct pattern of SOCS expression indicates Th lineage (Egwuagu et al. 2002; Seki et al. 2003). From the point of view of SOCS expression, our data revealed that the Th1/Th2 balance is toward Th1 immune activation in HTLV-I-infected individuals. We previously reported the importance of Th1 immune deviation in the development of HAM/TSP (Nakamura et al. 2000b). However, as far as the pattern of SOCS mRNA expression is concerned, there was no significant difference between HAM/TSP patients and HTLV-I-infected individuals without HAM/TSP. Nevertheless, the pattern of SOCS1 or SOCS3 mRNA expression showed the tendency that both IFN- $\gamma$ and IL-12 signaling are more up-regulated with more downregulated IL-4 signaling in HAM/TSP patients than in HTLV-I-infected individuals without HAM/TSP.

From these results, we thought that the expression of GATA-3, located downstream of IL$4 \mathrm{R}$, might be down-regulated in HTLV-I-infected individuals because of down-regulation of IL-4 signaling. However, unexpectedly, GATA-3 mRNA expression was also up-regulated in HAM/TSP patients than in HTLV-I-uninfected individuals. We are unable to precisely explain the reasons for this phenomenon. One possible explanation, however, is that auto-activation of GATA-3 itself might be involved (Ouyang et al. 2000). In this regard, there was moderate to strong correlation between T-bet and GATA-3 mRNA expression among HTLV-I-infected individuals with and without HAM/TSP. Therefore, Th1/Th2 balance in HTLV-I-infected individuals is under a compensatory control.

Thirdly, we analyzed mRNA expression of IL-12R $\beta 2$, which is located up-stream of STAT4 signaling and plays an important role in Th1 differentiation (Grogan and Locksley 2002). IL-12R $\beta 2$ mRNA expression in PBMC was significantly 
higher in HAM/TSP patients than in HTLV-Iuninfected individuals, strongly indicating that Th1 cells are increased in HAM/TSP patients. IL$12 \mathrm{R} \beta 2$ is induced by STAT4 signaling following the stimulation of IL-12 itself (Rogge et al. 1997). Therefore, down-regulation of SOCS3 mRNA expression in HAM/TSP patients might be involved in this phenomenon although the precise mechanisms are unclear.

Although mRNA expression of T-bet, GATA-3, IL-12R $\beta 2$ and SOCS1 seemed to be higher, and mRNA expression of SOCS3 seemed to be lower in HAM/TSP patients than in HTLVI-infected individuals without HAM/TSP, the differences were not statistically significant. Therefore, we, next, analyzed the correlation between these Th1-related cytokine signaling molecules and HTLV-I tax mRNA expression in both groups. Neither T-bet nor SOCS1 mRNA expression correlated with HTLV-I tax mRNA expression in HTLV-I-infected individuals with or without HAM/TSP, suggesting that HTLV-I tax expression is not directly related to expression of these signaling molecules. Interestingly, however, there was a moderately positive correlation between IL-12R $\beta 2$ and HTLV-I tax mRNA expression in HAM/TSP patients. Therefore, in patients with HAM/TSP, HTLV-I tax might be cooperatively involved in IL-12R/STAT4 signaling in HTLV-I-infected cells and contribute to Th1 activation. Recently, Furukawa et al. (2003) demonstrated that IFN- $\gamma$ producing cells in the population of HTLV-I tax-expressing cells are increased in HAM/TSP patients, compared to HTLV-I asymptomatic carriers with a high HTLV-I proviral load comparable to that in HAM/TSP patients. Further studies are needed to investigate at which step HTLV-I tax up-regulates IL-12R/STAT4 signaling pathway in patients with HAM/TSP.

\section{Acknowledgments}

Special thanks to Dr. Richard Yanagihara, University of Hawai'i at Manoa, for critical review of the manuscript.

This work was supported in part by a Research
Grant for Neuroimmunological Diseases from the Ministry of Health, Labor and Welfare, Japan.

\section{References}

Akizuki, S., Nakazato, O., Higuchi, Y., Tanabe, K., Setoguchi, M., Yoshida, S., Miyazaki, Y., Yamamoto, S., Sudou, S., Sannomiya, K. \& Okajima, T. (1987) Necropsy findings in HTLV-I associated myelopathy. Lancet, $\mathbf{1}$, 156-157.

Alexander, W.S. (2002) Suppressors of cytokine signaling (SOCS) in the immune system. Nat. Rev. Immunol., 2, 410-416.

Carvalho, E.M., Bacellar, O., Porto, A.F., Braga, S., Galvao-Castro, B. \& Neva, F. (2001) Cytokine profile and immunomodulation in asymptomatic human T-lymphotropic virus type 1-infected blood donors. J. Acquir. Immune. Defic. Syndr., 27, 1-6.

Egwuagu, C.E., Yu, C.-R., Zhang, M., Mahdi, R.M., Kim, S.J. \& Gery, I. (2002) Suppressors of cytokine signaling proteins are differentially expressed in Th1 and Th2 cells: implications for Th cell lineage commitment and maintenance. J. Immunol., 168, 3181-3187.

Furukawa, Y., Saito, M., Matsumoto, W., Usuku, K., Tanaka, Y., Izumo, S. \& Osame, M. (2003) Different cytokine production in Tax-expressing cells between patients with human $\mathrm{T}$ cell lymphotropic virus type I (HTLV-I)-associated myelopathy/tropical spastic paraparesis and asymptomatic HTLV-I carriers. J. Infect. Dis., 187, 1116-1125.

Furuya, T., Nakamura, T., Fujimoto, T., Nakane, S., Kambara, C., Shirabe, S., Hamasaki, S., Motomura, M. \& Eguchi, K. (1999) Elevated levels of interleukin-12 and interferon-gamma in patients with human $\mathrm{T}$ lymphotropic virus type I-associated myelopathy. J. Neuroimmunol., 95, 185-189.

Grogan, J.L. \& Locksley, R.M. (2002) T helper cell differentiation: on again, off again. Curr. Opin. Immunol., 14, 366-372.

Hanon, E., Goon, P., Taylor, G.P., Hasegawa, H., Tanaka, Y., Weber, J.N. \& Bangham, C.R. (2001) High production of interferon $\gamma$ but not interleukin-2 by human T-lymphotropic virus type I-infected peripheral blood mononuclear cells. Blood, 98, 721-726.

Hollsberg, P. (1999) Mechanisms of T-cell activation by human T-cell lymphotropic virus type I. $M i$ crobiol. Mol. Biol. Rev., 63, 308-333. 
Horiuchi, I., Kawano, Y., Yamasaki, K., Minohara, M., Furue, M., Taniwaki, T., Miyazaki, T. \& Kira, J. (2000) Th1 dominance in HAM/TSP and the optico-spinal form of multiple sclerosis versus Th2 dominance in mite antigen-specific $\operatorname{IgE}$ myelitis. J. Neurol. Sci., 172, 17-24.

Krebs, D.L. \& Hilton, D.J. (2001) SOCS proteins: negative regulators of cytokine signaling. Stem Cells., 19, 378-387.

Kuroda, Y. \& Matsui, M. (1993) Cerebrospinal fluid interferon-gammna is increased in HTLV-I-associated myelopathy. J. Neuroimmunol., 42, 223-226.

Losman, J.A., Chen, X.P., Hilton, D. \& Rothman, P. (1999) Cutting edge: SOCS-1 is a potent inhibitor of IL-4 signal transduction. J. Immunol., 162, 3770-3774.

Mogensen, T.H. \& Paludan, S.R. (2001) Molecular pathways in virus-induced cytokine production. Microbiol. Mol. Biol. Rev., 65, 131-150.

Murphy, K.M., Ouyang, W., Farrar, J.D., Yang, J., Ranganath, S., Asnagli, H., Afkarian, M. \& Murphy, T.L. (2000) Signaling and transcription in T helper development. Annu. Rev. Immunol., 18, 451-494.

Nakamura, T. (2000a) Immunopathogenesis of HTLV-I-associated myelopathy/tropical spastic paraparesis. Ann. Med., 32, 600-607.

Nakamura, T., Furuya, T., Nishiura, Y., Ichinose, K., Shirabe, S. \& Eguchi, K. (2000b) Importance of immune deviation toward Th1 in the early immunopathogenesis of human T-lymphotropic virus type I-associated myelopathy. Med. Hypotheses, 54, 777-782.

Nishiura, Y., Nakamura, T., Ichinose, K., Shirabe, S., Tsujino, A., Goto, H., Furuya, T. \& Nagataki, S. (1996) Increased production of inflammatory cytokines in cultured CD4+ cells from patients with HTLV-I-associated myelopathy. Tohoku J. Exp. Med., 179, 227-233.

Osame, M., Usuku, K., Izumo, S., Ijichi, N., Amitani, H., Igata, A., Matsumoto, M. \& Tara, M. (1986) HTLV-I associated myelopathy, a new clinical entity. Lancet, 1, 1031-1032.
Osame, M. (1990) Review of WHO Kagoshima meeting and diagnostic guidelines for HAM/TSP. In: Human Retrovirology: HTLV, edited by W.A. Blattner, Raven Press, New York, pp. 191-197.

Osame, M. (2002) Pathological mechanisms of human T-cell lymphotropic virus type I-associated myelopathy (HAM/TSP). J. Neurovirol., 8, 359-364.

O'Shea, J.J. \& Paul, W.E. (2002) Regulation of $\mathrm{T}_{\mathrm{H}} 1$ differentiation - controlling the controllers. Nat. Immunol., 3, 506-508.

Ouyang, W., Lohning, M., Gao, Z., Assenmacher, M., Ranganath, S., Radbruch, A. \& Murphy, K.M. (2000) Stat6-independent GATA-3 autoactivation directs IL-4-independent Th2 development and commitment. Immunity, 12, 27-37.

Rogge, L., Barberis-Maino, L., Biffi, M., Passini, N., Presky, D.H., Gubler, U. \& Sinigaglia, F. (1997) Selective expression of an interleukin-12 receptor component by human T helper 1 cells. $J$. Exp. Med., 185, 825-831.

Seki, Y., Inoue, H., Nagata, N., Hayashi, K., Fukuyama, S., Matsumoto, K., Komine, O., Hamano, S., Himeno, K., Inagaki-Ohara, K., Cacalano, N., O’Garra, A., Oshida, T., Saito, H., Johnston, J.A., Yoshimura, A. \& Kubo, M. (2003) SOCS-3 regulates onset and maintenance of TH2-mediated allergic responses. Nat. Med., 9, 1047-1054.

Szabo, S.J., Kim, S.T., Costa, G.L., Zhang, X., Fathman, C.G. \& Glimcher, L.H. (2000) A novel transcription factor, T-bet, directs Th1 lineage commitment. Cell, 100, 655-669.

Yasukawa, H., Sasaki, A. \& Yoshimura, A. (2000) Negative regulation of cytokine signaling pathways. Annu. Rev. Immunol., 18, 143-164.

Yoshida, M. (2001) Multiple viral strategies of HTLV-1 for dysregulation of cell growth control. Annu. Rev. Immunol., 19, 475-496.

Zheng, W. \& Flavell, R.A. (1997) The transcription factor GATA-3 is necessary and sufficient for Th2 cytokine gene expression in CD4 T cells. Cell, 89, 587-596. 